\title{
Os jovens das camadas populares na universidade pública: acesso e permanência
}

\author{
Rosileia Lucia Nierotka \\ Universidade Federal da Fronteira Sul (UFFS)
}

\author{
Joviles Vitório Trevisol \\ Universidade Federal da Fronteira Sul (UFFS)
}

Os jovens das camadas populares na universidade pública: acesso e permanência

Resumo: Recentemente, no Brasil, implementaram-se diversas políticas destinadas à ampliação do acesso dos jovens à educação superior. Iniciativas como REUNI, PROUNI e Lei das Cotas foram decisivas para o grande aumento do número de estudantes na Educação Superior. Este artigo descreve e analisa como as referidas políticas foram apropriadas e implementadas pelas universidades públicas brasileiras, tomando como referência empírica a Universidade Federal da Fronteira Sul (UFFS). Por meio de métodos e técnicas de pesquisa qualitativa (análise documental) e quantitativa (questionário institucional fechado), a pesquisa revelou significativa mudança no perfil dos jovens ingressantes na universidade pública em estudo. As políticas institucionais de acesso trouxeram para a universidade estudantes jovens, mulheres, com baixa escolaridade e renda familiar até três salários mínimos.

Palavras-chave: Políticas de educação superior. Juventude. Políticas de acesso. UFFS.

\section{Poor Youth at Public Universities: Access and permanence}

Abstract: Public policies have been recently implemented in Brazil to expand access of youth to higher education. Initiatives such as REUNI, PROUNI and quota laws were decisive for the strong increase in the number of students in higher education. This article describes and analyses how these policies were appropriated and implemented by Brazil's public universities, using as an empiric reference the Federal University at the Southern Border (UFFS). Using qualitative research methods and techniques (document analysis) and a quantitative method (a closed institutional questionnaire) the study revealed a significant change in the profile of the youth who have entered the public university studied. The institutional policies for access brought to the university youths and women with less educational preparation and family income up to three minimum wages.

Keywords: Higher education policies. Youth. Policies of access. UFFS. 


\section{Introdução}

Ao longo de toda a sua história, de um modo geral, as universidades têm sido espaços ocupados pelas elites detentoras do capital econômico, social e cultural. Os mais ricos têm usufruído dessa instituição milenar para legitimar a posição social que ocupam na estrutura social e ampliar o poder que, em geral, já exercem no conjunto da sociedade. Os jovens oriundos de famílias das classes média e alta são estimulados a ingressar nas melhores universidades e cursos em busca de um título acadêmico - que, na prática, é uma espécie de prêmio e de distinção - que lhes permitem exercer uma habilitação profissional socialmente legitimada (BOURDIEU, 2007; SOUSA SANTOS, 2005; RIBEIRO, 2006; FERNANDES, 2006). As instituições de ensino superior (IES) refletem, como espelhos, as desigualdades e a distribuição desigual do poder na sociedade.

O elitismo é uma característica marcante da educação superior na maioria dos países, inclusive no Brasil, cujo sistema superior ainda é marcadamente privatizado. De acordo com dados do Instituto Nacional de Pesquisas Educacionais (INEP), referentes ao ano de 2013, 87,4\% das IES brasileiras (2.090 ao todo) são privadas, e 12,6\% são públicas (301 IES). As matrículas, por conseguinte, refletem esse desequilíbrio: $74 \%$ dos estudantes em 2013, de um total de 7.305.977, estavam matriculados em IES privadas (MEC/INEP, 2013a). O elitismo também se evidencia claramente nos dados referentes à passagem dos estudantes do ensino médio para o ensino superior. Enquanto $87,3 \%$ dos alunos de ensino médio frequentam escolas públicas, no ensino superior esse percentual é de apenas 27\% (NIEROTKA, 2015). Os filhos dos mais pobres estudam em escolas públicas até o final da educação básica e, ao se depararem com as dificuldades de ingresso nas universidades públicas, decorrentes do limitado número de vagas e da concorrência, buscam as IES privadas para obterem sua formação de nível superior. As vagas públicas, por estas razões, têm sido historicamente ocupadas pelos estudantes de maior renda, formados em escolas privadas de educação básica. O dualismo estrutural que caracteriza o nosso sistema de ensino (escola gratuita para os pobres e escola paga para os ricos), analisado por autores como Romanelli (2012), Libâneo (2012) e Oliven (2005), se inverte no ensino superior, assumindo nova feição: universidade pública e gratuita para os ricos e privada para os pobres.

A democratização do acesso à educação superior, particularmente dos jovens de baixa renda, passou a ganhar espaço na agenda dos governos e da sociedade brasileira apenas nos anos recentes, desencadeando políticas públicas de expansão e interiorização das vagas, assim como ações afirmativas voltadas aos grupos sociais mais excluídos. O primeiro Projeto de Lei ( $\mathrm{PL} \mathrm{n}^{\circ}$ 73/99) submetido ao Congresso Nacional propondo reserva de 50\% das vagas das IES públicas para alunos provenientes de escolas públicas data de 1999. A matéria manteve-se em discussão ao longo de treze anos, até converter-se na Lei $n^{\circ} 12.711$ (Lei das Cotas), sancionada pela Presidenta Dilma Rousseff, em 29 de agosto de 2012. Os avanços e os retrocessos que integram o itinerário da Lei das Cotas revelam as disputas e as resistências em que determinados setores da sociedade colocam as políticas de combate às desigualdades sociais. As cotas nas universidades públicas foram objeto de contestação judicial em várias instâncias. O Superior Tribunal Federal recebeu, julgou e declarou im-

A democratização do acesso à educação superior, particularmente dos jovens de baixa renda, passou a ganhar espaço na agenda dos governos e da sociedade brasileira apenas nos anos recentes, desencadeando políticas públicas de expansão e interiorização das vagas, assim como ações afirmativas voltadas aos grupos sociais mais excluídos. procedente e ajuizada várias Ações Diretas de Inconstitucionalidade (ADI) que questionavam o PROUNI (Programa Universidade Para Todos), as leis estaduais do Rio de Janeiro e as políticas de cotas da Universidade de Brasília (SANTOS, 2012; NIEROTKA, 2015).

As políticas de expansão e democratização do acesso ao ensino superior, implementadas nos últimos anos por meio de programas e ações como o REUNI (Reestruturação e Expansão das Universidades Federais), o PROUNI (Programa Universidade Para Todos), o FIES (Fundo de Financiamento Estudantil), a Rede Federal de Educação Profissional, Científica e Tecnológica e a Lei das Cotas, produziram alguns resultados significativos. O número de matrículas cresceu em torno de 76\%, entre 2004 a 2013, passando de 4.163 .733 para 7.305.977. Nesse período foram criadas 18 novas universidades públicas federais. O número de campi passou de 148, em 2002, para 321, em 2014 (MEC/INEP, 2014a). A expansão, a despeito de sua inegável 
importância, elevou de forma modesta a presença dos jovens com idade entre 18 a 24 anos nas universidades. De acordo com dados de 2013, do total de jovens dessa faixa etária apenas 16,5\% encontravam-se matriculados em algum curso de nível superior (MEC/INEP, 2014a). O percentual obtido ficou bem abaixo dos 33\% estabelecidos pelo Plano Nacional de Educação (PNE), para o decênio 2001-2010, razão pela qual o PNE vigente, sancionado em 2014, manteve a meta e a adiou (33\% de escolarização líquida e 50\% de escolarização bruta) para o ano de 2024 (BRASIL, 2001, 2014).

$\mathrm{O}$ acesso dos jovens ao ensino superior, tendo presente o contexto descrito acima, é a problemática da investigação que deu origem a este artigo. A partir da contextualização das políticas públicas e das ações afirmativas implementadas nos últimos anos no Brasil, a pesquisa procurou compreender como tais políticas foram apropriadas e redimensionadas pelas IES. O presente texto centra-se na análise da efetividade e dos desdobramentos das políticas de acesso adotadas por uma universidade pública federal, com atuação nos três estados da Região Sul do Brasil, a Universidade Federal da Fronteira Sul (UFFS). A escolha dessa IES se deve ao caráter inovador de sua política de acesso, que transformou o perfil dos estudantes que ocupam as vagas disponibilizadas: $97,4 \%$ são egressos do ensino médio público e $69,3 \%$ pertencem a famílias com renda familiar média de até três salários mínimos.

\section{Método}

O método foi construído a partir dos objetivos da pesquisa e da tradição metodológica de estudos sobre políticas públicas. Optou-se por priorizar uma única IES, de natureza pública federal, criada em 2009 (Lei 12.029), no bojo das políticas de expansão do ensino superior público (REUNI). A instituição escolhida, a UFFS, atua nos três estados do Sul por meio de seus campi situados nas cidades de Laranjeiras do Sul (PR), Realeza (PR), Chapecó (SC), Erechim (RS), Passo Fundo (RS) e Cerro Largo (RS). Decidiu-se, também, estabelecer uma delimitação temporal para o estudo (2010-2015), definindo o ano de 2012 para o levantamento e a análise dos dados referentes ao perfil dos ingressantes naquele ano. A amostra para a pesquisa quantitativa ficou circunscrita, portanto, a 2.123 estudantes de graduação. O levantamento e a análise dos dados foram realizados no período entre agosto de 2013 a junho de 2015.

Assim delimitada, a pesquisa empírica passou a requerer, além de extensa revisão teórica, a obtenção e a análise de dados sobre três dimensões centrais: (i) as políticas de acesso e as ações afirmativas institucionais; (ii) o perfil dos ingressantes em 2012 e, (iii) a situação da matrícula dos estudantes após dois anos do seu ingresso. Cada uma das frentes exigiu abordagens metodológicas distintas, ora de natureza qualitativa, ora quantitativa.

O estudo sobre as políticas de acesso e ações afirmativas foi desenvolvido por meio de pesquisa documental, tendo envolvido a organização e a análise de uma gama de documentos institucionais, como lei de criação, estatuto, resoluções, portarias, editais, relatórios de pesquisa, informativos.

O segundo item, referente ao perfil dos ingressantes, foi desenvolvido por meio da tabulação e análise das informações disponíveis no Questionário Socioeconômico institucional, preenchido por cada estudante no ato de sua inscrição ao processo seletivo do ano de 2012. Foram consideradas as respostas dos que ingressaram naquele ano. Os referidos questionários receberam tratamento estatístico por meio do programa Statistical Package for Social Sciences (SPSS), em sua versão 21.0, o que tornou possível a elaboração de tabelas e gráficos e o cruzamentos de dados e comparações. Os dados institucionais foram enriquecidos por informações adicionais disponíveis no Censo Demográfico 2012 e Pesquisa Nacional de Amostra de Domicílios (PNAD/2012); Censo da Educação Básica 2012 (MEC/INEP); e, Censo da Educação Superior 2012 (MEC/INEP). Por fim, foram incorporados ao estudo alguns relatórios de pesquisa, dissertações e teses sobre a temática em questão.

O terceiro grupo de dados, referente à situação das matrículas após dois anos de ingresso na UFFS (2012-2014), foi obtido junto à Diretoria de Registro Acadêmico da UFFS.

\section{Principais resultados}

As universidades públicas federais criadas na última década foram desafiadas a se conceber a partir de projetos distintos e inovadores de educação superior. No contexto dos debates sobre as políticas de expansão, as problemáticas do elitismo, das desigualdades sociais e das assimetrias regionais ganharam centralidade, desafiando as novas IES a assumirem políticas de acesso mais arrojadas. A UFFS, assim como as demais IES, respondeu a esse desafio de forma sui generis, assumindo-se como a primeira universidade pública a implementar uma política de acesso centrada na escola pública, praticando percentuais muito acima dos exigidos pela Lei das Cotas. 


\subsection{Políticas de acesso e ações afirmativas}

O primeiro processo seletivo para ingresso de estudantes na UFFS foi realizado no início de 2010. Mantendo coerência com seu Projeto Político Institucional e diferenciando-se da maioria das instituições, o vestibular foi substituído por outro sistema de seleção, que utiliza o ENEM como prova de conhecimento básico, adicionando se à nota obtida neste exame um sistema de bonificação para cada um dos anos frequentados na escola pública, o denominado fator escola pública (FatorEP). O índice foi aplicado durante os três primeiros ingressos (2010, 2011 e 2012), sendo aprimorado em 2013, em virtude da aprovação da Lei das Cotas e pela adesão, em 2014, ao SISU (Sistema de Seleção Unificada). O FatorEP foi operado a partir dos seguintes critérios:

I) FatorEP = 1,3 - para o candidato que declarou ter cursado integralmente, com aprovação, todo o ensino médio em escola pública;

II) FatorEP = 1,2 - para o candidato que declarou ter cursado, com aprovação, apenas (duas) séries do ensino médio em escola pública;

III) FatorEP = 1,1 - para o candidato que declarou ter cursado, com aprovação, apenas (uma) série do ensino médio em escola pública;

IV) FatorEP = 1,0 - para os demais candidatos (UFFS, 2009, p. 4).

A aprovação da Lei das Cotas, em 2012, não obrigou a UFFS a readequar suas políticas de ingresso no que tange à escola pública, pois mais de $90 \%$ dos ingressantes nos anos anteriores haviam cursado ensino médio em escolas públicas. A adequação foi necessária apenas com relação aos aspectos étnico-raciais e renda. É importante destacar, como um aspecto inovador, que a UFFS não reservou apenas $50 \%$ de suas vagas para estudantes oriundos da escola pública, conforme prevê a Lei das Cotas, mas adotou, como critério para a reserva de vagas, o mesmo percentual de estudantes que conclui o ensino médio na escola pública, conforme o último senso da educação básica de cada ano e para cada Estado, em que estão localizados os campi da Instituição. Além disso, adotou, como ação afirmativa própria da Instituição, a reserva de um percentual de vagas para estudantes que estudaram parcialmente em escola pública.

Em 2013, a Instituição decidiu aderir ao Sistema de Seleção Unificada (SISU), utilizando este para a seleção de todos os cursos de graduação, inclusive para os cursos mais concorridos, como o de Medicina. No final daquele ano, o Conselho Universitário aprovou duas políticas de ações afirmativas, uma destinada aos estudantes indígenas (UFFS, 2013a) e, a segunda, para o acesso de estudantes haitianos (UFFS, 2013b). Em março de 2015 foi aprovada uma política voltada para o acesso e a permanência de estudantes e servidores com deficiência (UFFS, 2015).

O quadro a seguir sintetiza as principais políticas de acesso e ações afirmativas implementadas nos primeiros cinco anos de existência da Instituição:

\section{Quadro 1 - Políticas de acesso e ações afirmativas na UFFS (2010-2015)}

\begin{tabular}{|c|l|l|}
\hline \multicolumn{1}{|c|}{ Ano } & \multicolumn{1}{|c}{ Políticas de acesso } & \multicolumn{1}{c}{ Beneficiários } \\
\hline 2010 a 2012 & ENEM, Bonificação da escola pública. & Escola pública parcial e integral. \\
\hline 2013 & $\begin{array}{l}\text { ENEM, SISU, Lei 12.711/12 e ações afirmativas espe- } \\
\text { cíficas da UFFS. }\end{array}$ & $\begin{array}{l}\text { Escola pública (parcial e integral), pretos, pardos e } \\
\text { índios. }\end{array}$ \\
\hline \multirow{2}{*}{2014} & $\begin{array}{l}\text { ENEM, SISU, Lei 12.711/12, e ações afirmativas es- } \\
\text { pecíficas da UFFS.Processos seletivos especiais: } \\
\text { PROHAITI, PIN. }\end{array}$ & $\begin{array}{l}\text { Escola pública (parcial e integral), pretos, pardos, } \\
\text { índios e haitianos. }\end{array}$ \\
\hline \multirow{2}{*}{2015} & $\begin{array}{l}\text { ENEM, SISU, Lei 12.711 e ações afirmativas específi- } \\
\text { cas da UFFS. Processos seletivos especiais: } \\
\text { PROHAITI, PIN e política de acesso e permanência } \\
\text { de pessoas com deficiência. }\end{array}$ & $\begin{array}{l}\text { Escola pública (parcial e integral), pretos, pardos, } \\
\text { índiosonos e pessoas com deficiência. }\end{array}$ \\
\hline
\end{tabular}

Fonte: Elaboração própria. Montado a partir de NIEROTKA, 2015.

As políticas adotadas trouxeram para a universidade estudantes com um perfil que difere, em muito, ao da maioria das IES públicas. 


\subsection{Perfil dos ingressantes}

De acordo com os dados da pesquisa, a maioria dos estudantes ingressantes correspondem ao sexo feminimo, cujo percentual fica ligeiramente acima da média das IES no Brasil. A presença feminina é bastante expressiva $(63,5 \%)$, conforme demonstra a tabela 1.

Tabela 1 - Percentual da população brasileira e dos estudantes da UFFS, conforme sexo

\begin{tabular}{|l|c|c|c|}
\hline Sexo & UFFS (\%) & IES Brasil (\%) & População Brasil (\%) \\
\hline Masculino & 36,5 & 45,5 & 48,7 \\
\hline Feminino & 63,5 & 53,5 & 51,3 \\
\hline
\end{tabular}

Fonte: Elaboração própria. Montada a partir do Banco de Dados do Processo Seletivo 2012 DRA/PROGRAD/UFFS; IBGE, 2014; MEC/ INEP,2013b.

A presença feminina é mais acentuada em alguns cursos, cabendo destacar o de Pedagogia matutino e noturno (100\% e 97\%, respectivamente), Enfermagem (97,6\%), Nutrição (100\%), Letras noturno (86,2\%). A presença masculina é maior nos cursos das áreas de exatas e engenharias, cabendo destaque para o de Ciência da Computação (82\% no curso noturno e 81,6\% no matutino), Engenharia de Aquicultura (63,5\%), Agronomia (59\%, referente à média dos três cursos) e Ciências Econômicas noturno (57,6\%). Vários fatores ajudam a entender essa composição, particularmente o da divisão social e sexual do trabalho existente na sociedade e a decorrente desigualdade de remuneração entre as carreiras ditas femininas e as consideradas masculinas (RISTOFF et al., 2007).

Quanto ao quesito idade, 71,5\% dos estudantes da UFFS são jovens entre 18 a 24 anos. A distorção idade/série é menor que a média regional e nacional, o que demonstra um importante avanço no sentido de ampliar a presença dos jovens em idade universitária ideal.

Tabela 2 - Idade dos estudantes da UFFS, das IES da Região Sul e do Brasil, em 2012

\begin{tabular}{|l|c|c|c|}
\hline Faixa etária & UFFS (\%) & IES Região Sul $(\%)$ & IES Brasil $(\%)$ \\
\hline Menos de 18 anos & 0,1 & 0,5 & 0,4 \\
\hline De 18 a 24 anos & 71,5 & 54,1 & 50,5 \\
\hline De 25 a 29 anos & 14,8 & 19,5 & 20,4 \\
\hline Mais de 30 anos & 13,6 & 25,9 & 28,7 \\
\hline
\end{tabular}

Fonte: Elaboração própria. Montada a partir do Banco de Dados do Processo Seletivo 2012 DRA/PROGRAD/UFFS eMEC/INEP, 2014 b.

Cabe observar também que a média da UFFS está bem acima da taxa líquida de jovens entre 18 a 24 anos na universidade brasileira, estimada em 16,5\% (MEC/INEP, 2014a), e também acima da meta estabelecida pelo Plano Nacional de Educação para 2024 (33\% de escolarização líquida e 50\% de escolarização bruta). A distorção idade/série na educação superior é um desafio de grandes dimensões, e sua exequibilidade depende também dos avanços obtidos no ensino médio no sentido de elevar os percentuais de concluintes na idade apropriada. Em 2014, cerca de 29,5\% dos estudantes desse nível de ensino não estavam na série correta.

A pesquisa procurou conhecer os aspectos étnico-raciais dos ingressantes: $85,5 \%$ dos estudantes se autodeclaram brancos e $14,5 \%$ de pretos, pardos, indígenas ou amarelos. Como se pode verificar na tabela abaixo, a UFFS, como de resto, toda a universidade brasileira, tem cor. A despeito de o Brasil ser um país de maioria negra, as IES têm sido ocupadas pela elite branca, no âmbito das quais as desigualdades sociais e econômicas se expressam, se reproduzem e se legitimam socialmente.

Tabela 3 - Composição étnico-racial dos estudantes da UFFS e das IES da Região Sul, em 2012

\begin{tabular}{|l|c|c|c|}
\hline Composição étnico-racial & UFFS (\%) & IES Região Sul (\%) & Região Sul (\%) \\
\hline Preta, parda, indígena e amarela & 14,5 & 11,6 & 23,6 \\
\hline Branca & 85,5 & 88,4 & 76,4 \\
\hline
\end{tabular}

Fonte: Elaboração própria. Montada a partir do Banco de Dados do Processo Seletivo 2012 DRA/PROGRAD/UFFS; IBGE, 2014; MEC/ INEP,2014b. 
Os dados refletem a histórica exclusão social e educacional dos negros e dos indígenas. A universidade, em termos sociológicos, abriu-se para acolher os ricos e os brancos, majoritariamente descendentes de europeus, e fechou suas portas para os indígenas e os descendentes de africanos, submetendo-os ao regime de escravidão por longos séculos e ao analfabetismo (RIBEIRO, 2006; MEC/SEPIR, 2004).

A pesquisa revelou também que os estudantes são, na sua grande maioria, urbanos. Apenas $26,8 \%$ informaram estar residindo no meio rural, percentual, a propósito, um pouco acima da média registrada na Região Sul e no Brasil.

Tabela 4 - Local da moradia dos estudantes da UFFS, da região Sul e do Brasil, em 2012

\begin{tabular}{|l|c|c|c|}
\hline Local de Moradia & UFFS $(\boldsymbol{\%})$ & Região Sul (\%) & Brasil (\%) \\
\hline Rural & 26,8 & 14,8 & 15,2 \\
\hline Urbano & 73,2 & 85,2 & 84,8 \\
\hline
\end{tabular}

Fonte: Elaboração própria. Montada a partir do Banco de Dados do Processo Seletivo 2012 DRA/PROGRAD/UFFS e IBGE, 2014.

Constatou-se também que a maioria dos estudantes reside nos municípios que integram a região de abrangência da UFFS: 85,9\% vivem em localidades próximas do campus universitário (até $90 \mathrm{~km}$ de distância) e 98,6\% são oriundos da Região Sul. O modelo multicampi interioriza e aproxima a IES ao espaço onde os acadêmicos vivem e trabalham.

Os estudantes são, na sua maioria, trabalhadores, ou seja, mais de 50\% possuíam vínculo empregatício com remuneração de tempo integral ou de tempo parcial. Cerca de 30\% declararam serem apenas estudantes.

\section{Tabela 5 - Vínculo empregatício dos estudantes da UFFS, em 2012}

\begin{tabular}{|l|c|}
\hline Vínculo empregatício & $(\boldsymbol{\%})$ \\
\hline Trabalho em tempo integral remunerado & 40,8 \\
Não trabalho & 28,8 \\
Não trabalho, mas procuro por um trabalho & 11,9 \\
Trabalho em tempo parcial remunerado & 11,6 \\
Outro (tarefas domésticas, freelance etc.) & 5,0 \\
Trabalho em tempo parcial sem remuneração & 1,9 \\
\hline
\end{tabular}

Fonte: Elaboração própria. Montada a partir do Banco de Dados do Processo Seletivo 2012 DRA/PROGRAD/UFFS.

Quanto à condição socioeconômica dos estudantes, a pesquisa revelou que a maioria (69,3\%) possui renda média mensal familiar de até três salários mínimos, conforme a tabela 6 .

Tabela 6 - Renda média mensal dos estudantes da UFFS, da Região Sul e do Brasil, em 2012

\begin{tabular}{|l|c|c|c|}
\hline Renda média familiar & UFFS $(\boldsymbol{\%})$ & Região Sul $(\boldsymbol{\%})$ & Brasil $(\mathbf{\%})$ \\
\hline Até 3 salários mínimos & 69,3 & 58,0 & 56,6 \\
\hline Mais de 3 salários mínimos & 30,3 & 15,7 & 12,2 \\
\hline Sem rendimento & 0,3 & 25,0 & 28,9 \\
\hline Não declarada renda & - & 1,3 & 2 \\
\hline
\end{tabular}

Fonte: Elaboração própria. Montada a partir dos Dados do Processo Seletivo 2012 DRA/PROGRAD/UFFS ePNAD 2012, IBGE, 2014.

De acordo com os dados, são estudantes trabalhadores, oriundos de famílias com baixa renda e pertencentes às classes D e E. A gratuidade da educação superior pública é apropriada, neste caso, pelos setores sociais que mais precisam do financiamento público. O elitismo abre espaço para concepções mais democráticas e inclusivas de ensino superior. 


\subsection{Origem escolar dos ingressantes}

Com relação à origem escolar dos ingressantes na UFFS, em 2012, identificou-se que 97,4\% cursaram a maior parte ou todo o ensino médio em escolas públicas. A tabela abaixo detalha os percentuais de escola pública por ano, dos ingressantes na UFFS, por campus, considerando todas as formas de ingresso (ENEM, processo seletivo especial, transferência).

Tabela 7 - Percentual de estudantes da UFFS oriundos do ensino médio público (2010-2014)

\begin{tabular}{|c|c|}
\hline Ano & Escola Pública (\%) \\
\hline 2010 & 94,0 \\
2011 & 94,8 \\
2012 & 93,6 \\
2013 & 92,0 \\
2014 & 90,4 \\
\hline
\end{tabular}

Fonte: Sistema de GestãoAcadêmica(SGA)/Diretoria de RegistroAcadêmico/UFFS, 2014.

Os percentuais de escola pública variam ligeiramente entre os campi que constituem a UFFS, cabendo destacar que o menor percentual está em Passo Fundo, campus que sedia um dos cursos de Medicina.

Tabela 8 - Média do percentual de escola pública entre os campi da UFFS (2010-2014)

\begin{tabular}{|c|c|}
\hline Campus & Escola Pública (\%) \\
\hline Chapecó & 90,5 \\
\hline Laranjeiras do Sul & 96,7 \\
Realeza & 97,3 \\
Cerro Largo & 94,5 \\
Erechim & 89,8 \\
\hline Passo Fundo & 86,6 \\
\hline
\end{tabular}

Fonte: Sistema de GestãoAcadêmica(SGA)/Diretoria de RegistroAcadêmico/UFFS, 2014.

Os percentuais são expressivos e ficam bem acima da média nacional. Tomando como referência uma pesquisa realizada pela Andifes/Fonaprace (2011), referente aos ingressantes do ano de 2010, 44,8\% dos estudantes das IES públicas federais brasileiras eram oriundos exclusivamente de escolas públicas e, na Região Sul, 50,6\%.

Outro aspecto que chama a atenção sobre a origem escolar dos estudantes é a escolaridade média dos pais e das mães. Conforme demonstra a tabela abaixo, constatou-se que $44,5 \%$ dos pais e $36,1 \%$ das mães estudaram somente até a $4^{\circ}$ série do ensino fundamental e apenas $6,6 \%$ e $12,9 \%$, respectivamente, concluíram o curso superior. Os estudantes, na sua maioria, além de estar frequentando o primeiro curso de graduação, constituem a primeira geração da família a acessar a educação superior. As mães, em média, possuem maior escolaridade que os pais. Enquanto 4,9\% dos pais declaram ter concluído o ensino superior, o percentual feminino chega a 7,9\%.

\section{Tabela 9 - Grau de escolaridade dos pais e mães dos estudantes}

\begin{tabular}{|l|c|c|}
\hline Grau de escolaridade & Pais $(\%)$ & Mães $(\%)$ \\
\hline Da $1^{\circ}$ a $4^{\circ}$ série & 44,5 & 36,1 \\
Da $5^{\circ}$ a $8^{\circ}$ série & 25,5 & 23,0 \\
Ensino médio & 20,3 & 25,4 \\
Ensino superior & 4,9 & 7,9 \\
Pós-graduação & 1,7 & 5,0 \\
Não estudou & 3,1 & 2,5 \\
\hline
\end{tabular}

Fonte: Elaboração própria. Montada a partir do Banco de Dados do Processo Seletivo 2012 DRA/PROGRAD/UFFS. 
A significativa presença de egressos do ensino médio público na UFFS sinaliza uma mudança qualitativa nas políticas de ingresso nas IES públicas federais, cujo principal objetivo é enfrentar o dualismo estrutural que perpassa a educação brasileira. $\mathrm{O}$ gráfico abaixo traz alguns indicadores que dimensionam o elitismo, ainda muito presente, na passagem do ensino médio para o ensino superior. Enquanto 87,3\% dos alunos de ensino médio frequentam escolas públicas, no ensino superior esse percentual é de apenas $27 \%$ :

\section{Gráfico 1 - Natureza administrativa das matrículas do Ensino Médio e Superior no Brasil e na Região Sul, em 2012}

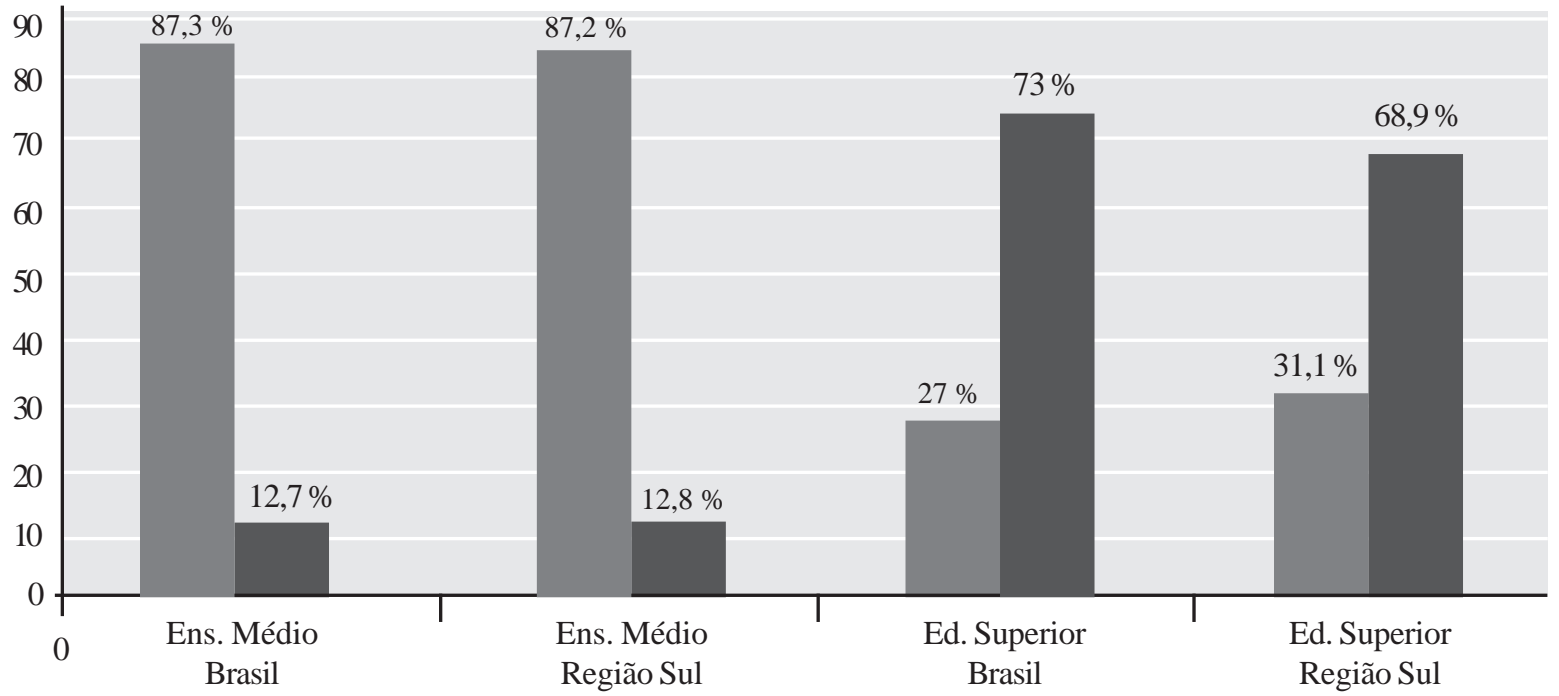

Público

Privado

Fonte: Elaboração própria. Montada a partir do Banco de Dados do Processo Seletivo 2012 DRA/PROGRAD/UFFS e MEC/INEP (2014b;2014c).

\subsection{Situação da matrícula dos ingressantes}

Tendo em vista a origem social e escolar dos ingressantes, a pesquisa levantou dados sobre a permanência, centrando a análise sobre o percurso dos estudantes nos dois primeiros anos após o ingresso (20122014). Constatou-se que 66,1\% dos matriculados no primeiro semestre de 2012 permaneciam com sua matrícula ativa no final do primeiro semestre de $2014^{2}$, contra $33,9 \%$ de desistentes ${ }^{3}$. Entre os cursos da UFFS com maior percentual de abandono/evasão estão as licenciaturas em Ciências Sociais Matutino $(75,9 \%)$, Interdisciplinar em Educação no Campo Noturno (69,7\%), Geografia Matutino (51,9\%) e o curso bacharel em Engenharia de Aquicultura Integral (51,9\%). Os cursos de Enfermagem (90,2\%), Medicina Veterinária $(82,0 \%)$ e Agronomia $(78,6 \%$, referente à média dos três cursos existentes) são os que apresentam os maiores percentuais de retenção.

$\mathrm{O}$ percentual de abandono, ainda que seja preocupante, está bastante próximo à média nacional. De acordo com Ristoff (2013), o índice de concluintes em cursos nas IES brasileiras é de 60\%, sendo as IES privadas as que apresentam os maiores percentuais de conclusão. De acordo com Ristoff (2013, p. 40), ao analisar os dados do INEP sobre essa questão, no período de 1991 a 2011, constata-se que "as gerações mais recentes vêm enfrentando mais dificuldades para se graduarem, chegando em 2011 com uma taxa de sucesso de apenas 44\%". A Região Sul, desde 1994, mantém a menor taxa de conclusão: em 2011, apenas 39\% dos estudantes concluíram o curso iniciado quatro anos antes. Sobre isso, Costa et al. (2014) explicam que o abandano incide mais sobre o primeiro ano de ingresso, pois se trata do período que apresenta as maiores dificuldades de adaptação e de integração ao contexto universitário.

Cabe considerar também que a desistência do curso nem sempre implica evasão do sistema de ensino superior. Parte dos desistentes migra para outros cursos e instituições, na mesma região ou para outras. A mobilidade acadêmica é real, típica da atual geração de jovens que buscam aliar, ao máximo, as decisões pessoais às 
expectativas concretas de sucesso profissional e de realização (RISTOFF, 1999). O abandono e a mobilidade acadêmica devem-se a muitos fatores, tendo peso importante a falta de prestígio e os baixos salários da profissão pretendida. Os cursos de licenciaturas são os que apresentam os maiores percentuais de desistentes e isso tem relação direta com a remuneração da carreira e com o baixo reconhecimento social da profissão.

Independentemente das causas, o abandono indica que é necessário conceber as políticas de acesso de forma integrada às políticas de permanência. Como destacam Costa et al. (2014), o sucesso escolar e universitário deve ser uma meta fundamental. O insucesso e o abandono precisam ser considerados como problemas, seja para os estudantes diretamente envolvidos, seja para o sistema educacional e a sociedade como um todo.

\section{Considerações finais}

A análise realizada neste estudo revela que, sob o prisma do acesso às IES públicas federais, as políticas implantadas trouxeram para a instituição novos públicos estudantis, pertencentes a grupos sociais, econômicos, étnicos e geracionais historicamente excluídos. Entre os estudantes pesquisados, em termos quantitativos, há mulheres (63,5\%), jovens ( $71,5 \%$ entre 18 a 24 anos), brancos $(85,5 \%)$, urbanos $(73,2 \%)$, trabalhadores $(52,7 \%)$, de baixa renda $(69,3 \%$ com renda familiar de até três salários mínimos), oriundos da escola pública (acima de $90 \%$ ) e pertencentes a famílias com baixa escolaridade (apenas $4,9 \%$ e $7,9 \%$ dos pais e das mães, respectivamente, possuem ensino superior). Ou seja, as políticas e as ações afirmativas implementadas abriram a universidade para os jovens das camadas populares. $\mathrm{O}$ acesso, a despeito de ser apenas uma das dimensões de um processo mais amplo de democratização da universidade, é um elemento fundamental na medida em que desafia a IES a se conceber e a se realizar como um bem público a serviço da sociedade. A inclusão promove a justiça cognitiva, permite aos excluídos a apropriação dos saberes sistematizados, do conhecimento e da tecnologia historicamente construídos, essenciais ao mundo do trabalho e ao exercício da cidadania (SOUSA SANTOS, 2004; DIAS SOBRINHO, 2010). Trata-se de uma resposta ao monopólio elitizado do saber e uma ampliação dos compromissos éticos e políticos da formação e do conhecimento que a universidade produz. A justiça cognitiva contribui, desta maneira, com a justiça social (ARROYO, 2011).

Os dados revelam que a UFFS, por meio de suas políticas de acesso, vem procurando responder ao histórico de elitismo na educação superior. A presença dos jovens das camadas populares, trabalhadores e oriundos da escola pública desafia a universidade pública sobre diferentes aspectos, entre os quais o da permanência. Os índices de estudantes desistentes da UFFS são significativos e indicam a necessidade de políticas de permanência e de uma pedagogia universitária mais atenta às especifidades desse universo juvenil.

\section{Referências}

ANDIFES - Associação Nacional dos Dirigentes de Instituições Federais de Ensino Superior. Perfil socioeconômico e cultural dos estudantes de graduação das Universidades Federais. Brasília: Fórum Nacional de Pró-Reitores de Assuntos Comunitários e Estudantis (FONAPRACE), 2011.

ARROYO, M. Currículo. Território em disputa. Petrópolis: Vozes, 2011.

BRASIL. Presidência da República. Lei 10.172, de 09 de janeiro de 2001. Aprova o Plano Nacional de Educação e dá outras providências. Diário Oficial da União, Brasília, DF, Seção 1, p. 1, 10 de jan. 2001.

. Lei n. 12.029, de 15 de setembro de 2009. Dispõe sobre a criação da Universidade Federal da Fronteira Sul. Diário Oficial da

União, Brasília, DF, Seção 1, p. 1, 16 set. 2009.

Presidência da República. Lei n. 12.711, em 29 de agosto de 2012. Dispõe sobre o ingresso nas universidades federais e nas instituições federais de ensino técnico de nível médio e dá outras providências. Diário Oficial da União, Brasília, DF, Seção 1, p. 1, 30 ago. 2012.

. Presidência da República. Lei n. 13.005, de 25 de junho de 2014. Aprova o Plano Nacional de Educação (PNE) e dá outras providências. Diário Oficial da União, Brasília, DF, Seção 1, p. 1, 26 jun. 2014.

BOURDIEU, P. A escola conservadora: as desigualdades frente à escola e à cultura. Tradução de Aparecida Joly Gouveia. In: NOGUEIRA, M. A.; CATANI, A. (Orgs.). Pierre Bourdieu: escritos de educação. Petrópolis: Vozes, 2007.

COSTA, A. F. et al. Um modelo teórico e metodológico: análise do sucesso, insucesso e abandono no ensino superior. In: COSTA, A. F.; LOPES, J. T.; CAETANO, A. (org.). Percursos de estudantes no ensino superior: fatores e processos de sucesso e insucesso. Lisboa: Mundos Sociais, 2014.

DIAS SOBRINHO, J. Democratização, qualidade e crise da educação superior: faces da exclusão e limites da inclusão. Educação \& Sociedade, Campinas, v. 31, n. 113, p. 1.223-1.245, out./dez. 2010.

FERNANDES, F. A revolução burguesa no Brasil: ensaio de interpretação sociológica. São Paulo: Globo, 2006. 
INSTITUTO BRASILEIRO DE GEOGRAFIA E ESTATÍSTICA (IBGE). Pesquisa Nacional por Amostra de Domicílios. Banco de dados agregados. Sistema IBGE de Recuperação Automática (SIDRA). Disponível em: <http://www.sidra.ibge.gov.br/pnad/ default.asp?o=1\&i=P>. Acesso em: 17 out. 2014.

LIBÂNEO, J. C. O dualismo perverso da escola pública brasileira: escola do conhecimento para os ricos, escola do acolhimento social para os pobres. Educação e Pesquisa, São Paulo, v. 38, n. 1, p. 13-28, 2012.

MEC/SEPIR - Ministério da Educação/Secretaria Especial de Promoção da Igualdade Racial. Diretrizes curriculares nacionais para a educação das relações étnico-raciais e para o ensino de história e cultura afro-brasileira e africana. Brasília, DF: MEC/SEPIR, out. 2004. MEC/INEP - Ministério da Educação/Instituto Nacional de Estudos e Pesquisas Educacionais Anísio Teixeira. Senso da Educação Superior 2013. 2013a. 25 slides. Disponível em: <http://download.inep.gov.br/educacao_superior/censo_superior/apresentacao/2014/ coletiva_censo_superior_2013.pdf $>$. Acesso em: 09 fev. 2015.

. Principais resultados do Censo 2012. II Encontro Nacional do Censo da Educação Superior. Foz do Iguaçu, PR, nov. 2013 b. 37

slides. Disponível em: <http://portal.inep.gov.br/web/censo-da-educacao-superior/encontro-nacional>. Acesso em: 20 jun. 2014.

.Censo da Educação Superior. Disponível em: <http://portal.inep.gov.br/web/censo-da-educacao-superior>. Acesso em: 01 jul. $2014 \mathrm{a}$. . Sinopses Estatísticas da Educação Superior - Graduação. Disponível em: <http://portal.inep.gov.br/superior-censosuperiorsinopse>. Acesso em: 21 out. 2014b.

Sinopses Estatísticas da Educação Básica. Disponível em: <http://portal.inep.gov.br/basica-censo-escolar-sinopse-sinopse>. Acesso em: 21 out. 2014c.

NIEROTKA, R. L. Políticas de acesso e ações afirmativas na educação superior: a experiência da Universidade Federal da Fronteira Sul. 2015. 179 f. Dissertação (Mestrado em Educação) - Universidade Federal da Fronteira Sul. Chapecó, 2015.

OLIVEN, A. C. A marca de origem: comparando colleges norte americanos e faculdades brasileiras. Cadernos de Pesquisa, v. 35, n. 125, p. 111-135, mar./ago. 2005.

RIBEIRO, D. O povo brasileiro: a formação e o sentido do Brasil. São Paulo: Companhia das Letras, 2006.

RISTOFF, D. Universidade em foco: reflexões sobre a Educação Superior. Florianópolis: Insular, 1999.

Vinte e um anos de educação superior, expansão e democratização. Grupo Estratégico de análise da Educação Superior no Brasil,

Cadernos do GEA, n. 3, jan./jun. 2013. Rio de Janeiro: FLACSO/GEA/UERJ/LPP, 2013.

. et al (org.). A mulher na educação superior brasileira: 1991-2005. Brasília: Instituto Nacional de Estudos e Pesquisas

Educacionais Anísio Teixeira, 2007.

ROMANELLI, O. História da educação no Brasil (1930/1973). Petrópolis: Vozes, 2012.

SANTOS, A. P. Itinerário das ações afirmativas no ensino superior público brasileiro: dos ecos de Durban à Lei das Cotas. Revista de Ciências Humanas, Viçosa, v. 12, n. 2, p. 289 317, jul./dez. 2012.

SOUSA SANTOS, B. Para uma sociologia das ausências e uma sociologia das emergências. In: SANTOS, B. S. S. (Org.) Conhecimento prudente para uma vida decente. Um discurso sobre as ciências revisitado. São Paulo: Cortez, 2004.

A universidade no século XXI. Para uma reforma democrática e emancipatória da Universidade. São Paulo: Cortez, 2005.

UFFS - Universidade Federal da Fronteira Sul. Edital n. 003/UFFS/2009. 25 de nov. 2009.

. Edital n. 162/UFFS/2011, de 08 de novembro de 2011. Processo Seletivo de 2012.

. Edital n. 311/UFFS/2012, 11 de dezembro de 2012. Processo Seletivo de 2013.

Resolução n. 32/2013 - CONSUNI. Institui o Programa de Acesso à Educação Superior da UFFS para estudantes haitianos -

PROHAITI e dispõe sobre os procedimentos para operacionalização das atividades do programa. Sala das Sessões do Conselho Universitário, $11^{\text {a }}$ Sessão Ordinária, Chapecó, SC, 12 dez. 2013a.

. Resolução n. 33/2013 - CONSUNI. Institui o Programa de Acesso e Permanência dos Povos Indígenas (PIN) da Universidade

Federal da Fronteira Sul. Sala das Sessões do Conselho Universitário, $11^{a}$ Sessão Ordinária, Chapecó, SC, 12 dez. 2013 b.

. Resolução n. 4/2015 - CONSUNI/CGRAD. Política de acesso e permanência da pessoa com deficiência, transtornos globais do desenvolvimento e altas habilidades/ superdotação na UFFS. Sala de Reuniões da Câmara de Graduação do Conselho Universitário, $2^{\mathrm{a}}$ Reunião Ordinária, Chapecó, SC, 19 mar. 2015.

\section{Notas}

1 A média foi considerada apenas entre os anos de 2013 e 2014, a partir da criação do Campus e do curso de Medicina.

2 Contempla os estudantes com a situação acadêmica nas seguintes condições: matrícula ativa, transferência interna, matrícula aditada e matrícula trancada.

3 Contempla os estudantes com a situação acadêmica nas seguintes condições: matrícula cancelada, eliminado, aluno desistente e aluno transferido.

\section{Rosileia Lucia Nierotka}

rosileia@uffs.edu.br

Mestre em Educação pela Universidade Federal da Fronteira Sul (UFFS) 
Graduada em Serviço Social pela Universidade Comunitária Regional de Chapecó Assistente Social na UFFS atuando junto ao Setor de Assuntos Estudantis

\section{Joviles Vitório Trevisol}

joviles.trevisol@uffs.edu.br

Doutor em Sociologia pela Universidade de São Paulo,

Docente do Programa de Pós-graduação em Educação da Universidade Federal da Fronteira Sul (UFFS)

\section{UFFS}

Campus Chapecó

Rodovia SC 484, KM 02

Chapecó - Santa Catarina - Brasil

CEP: 89801-001

\section{UFFS}

Unidade General Osório

Avenida General Osório, 413 D, Bairro Jardim Itália

Chapecó - Santa Catarina - Brasil

CEP: 89802-210 